\title{
A new gelator based on tetraphenylethylene and diphenylalanine: Gel formation and reversible fluorescence tuning
}

\author{
SUN Fei, ZHANG GuanXin \& ZHANG DeQing* \\ Beijing National Laboratory for Molecular Sciences, Organic Solids Laboratory, Institute of Chemistry, Chinese Academy of Sciences, Beijing \\ 100190, China
}

Received April 18, 2012; accepted May 17, 2012; published online September 25, 2012

\begin{abstract}
A new gelator 1 based on tetraphenylethylene (TPE) and diphenylalanine was designed and synthesized. Compound 1 was non-emissive in solution, but its fluorescence turned on after the formation of gels, due to the aggregation-induced emission (AIE) feature of TPE. Interestingly, the fluorescence was reversibly switched "on-off" upon the "gel-sol" transition. Scanning electron microscope (SEM), confocal laser scanning microscope (CLSM) and X-ray diffraction (XRD) were employed to study the gels.
\end{abstract}

tetraphenylethylene, diphenylalanine, gel, aggregation-induced emission (AIE)

Citation: Sun F, Zhang G X, Zhang D Q. A new gelator based on tetraphenylethylene and diphenylalanine: Gel formation and reversible fluorescence tuning. Chin Sci Bull, 2012, 57: 4284-4288, doi: 10.1007/s11434-012-5430-6

It is known that low-molecular-weight gelators (LMWGs) are able to immobilize certain solvents at low concentrations (less than $5 \%$ in weight percentage), due to weak intermolecular interactions, such as hydrogen bonding, van der waals force, $\pi-\pi$ stacking and hydrophobic effect, etc. These gelator molecules can self-assemble into threedimensional (3D) networks leading to gel formation [1,2]. A number of organic compounds have been investigated for the development of gelators, including cholesterol derivatives [3-5], amides and urea derivatives [6-9], nucleotides [10], saccharides [11-13], amino acids and peptides [14-22], oligo(para-phenylene vinylene) derivatives [23-25] and dendrimers [26-29]. Gelators can be categorized into organogelators and hydrogelators.

Currently, more efforts have been paid to fabricate multi-responsive or multi-functional smart gels. However, there are only a few reports about tuning the fluorescence upon gel-solution (gel-sol) transition [9,23,29-32]. In this report, we describe a new gelator $\mathbf{1}$ based on tetraphenylethylene (TPE) and diphenylalanine, in which TPE is well-known for the aggregation-induced emission (AIE)

*Corresponding author (email: dqzhang@iccas.ac.cn) feature [33-35] and diphenylalanine is extensively utilized to develop hydrogelators [14-16]. The results reveal that $\mathbf{1}$ can gelate several solvent systems and the fluorescence can be reversibly tuned upon gel-sol transition.

\section{Experimental}

\subsection{Materials and characterization techniques}

4-Methoxybenzophenone 2 was purchased from Alfa Aesar and diphenylalanine $\mathbf{6}$ was purchased from GL Biochem (Shanghai) Ltd, and they were used as received. Compounds 3 and $\mathbf{4}$ were prepared according to reported procedures [29].

${ }^{1} \mathrm{H}$ NMR and ${ }^{13} \mathrm{C}$ NMR spectra were recorded on Bruker Avance $400 \mathrm{MHz}$. High-resolution mass spectra (HRMS) were obtained with Bruker Apex II FT-ICRMS. Fluorescence spectra were measured with a Hitachi F-4500 spectrometer. Scanning electron microscope (SEM) images were studied on a Hitachi S-4800 microscope. Confocal laser scanning microscope (CLSM) imaging experiments were performed with an Olympus FV-1000 laser scanning microscopy system. X-ray diffraction (XRD) data were 
collected with Rigaku D/max 2500.

\subsection{Synthesis}

The synthesis started from 4-methoxybenzophenone $\mathbf{2}$ and this was self-coupled into compound $\mathbf{3}$, which was demethylated to get compound $\mathbf{4}$. Reaction of compound $\mathbf{4}$ with bromoacetate and subsequent hydrolysis led to compound $\mathbf{5}$. In the presence of NHS and DCC, compound $\mathbf{5}$ was activated and further reacted with diphenylalanine $\mathbf{6}$ to afford compound 1 (Figure 1).

Synthesis of 5: To a flask were added compound 4 (410 $\mathrm{mg}, 1.08 \mathrm{mmol})$, ethyl bromoacetate $(0.6 \mathrm{~mL}, 5.4 \mathrm{mmol})$, $\mathrm{K}_{2} \mathrm{CO}_{3}(1.5 \mathrm{~g}, 10.9 \mathrm{mmol})$ and anhydrous $\mathrm{CH}_{3} \mathrm{CN}(25 \mathrm{~mL})$ under nitrogen atmosphere. The mixture was heated to reflux and stirred for $8 \mathrm{~h}$. After the reaction was complete, water $(20 \mathrm{~mL})$ and $\mathrm{CH}_{2} \mathrm{Cl}_{2}(20 \mathrm{~mL})$ were added. The organic layer was extracted and washed successively with brine and water, and dried over anhydrous $\mathrm{MgSO}_{4}$. After filtration, the solvent was evaporated under reduced pressure. The yellowish residue was dissolved in a mixture of $\mathrm{CH}_{3} \mathrm{OH}(6.4 \mathrm{~mL})$ and $\mathrm{H}_{2} \mathrm{O}(0.8 \mathrm{~mL})$, and $\mathrm{KOH}$ (300 mg, 5.4 $\mathrm{mmol})$ was further added. The mixture was heated to reflux and stirred for $4 \mathrm{~h}$. After being cooled to room temperature, the solvent was evaporated under reduced pressure. Water $(20 \mathrm{~mL})$ and $3 \mathrm{~mol} / \mathrm{L} \mathrm{HCl}(\mathrm{aq})$ were added by droplets until the residue was completely dissolved ( $\mathrm{pH}$ 1.0). The mixture was taken up in $\mathrm{CH}_{2} \mathrm{Cl}_{2}$ and the organic layer was washed successively with brine and water, and dried over anhydrous $\mathrm{MgSO}_{4}$. After filtration and evaporation, the residue was subjected to column chromatography with $\mathrm{CH}_{2} \mathrm{Cl}_{2} / \mathrm{CH}_{3} \mathrm{OH}$ (v/v, 200/1) as eluant. Compound $\mathbf{5}$ was obtained as a yellowish powder $\left(340 \mathrm{mg}\right.$ ) in $72 \%$ yield. ${ }^{1} \mathrm{H} \mathrm{NMR}(400 \mathrm{MHz}$, $\left.\mathrm{CDCl}_{3}\right): \delta 7.20-6.85(14 \mathrm{H}, \mathrm{m}), 6.75-6.55(4 \mathrm{H}, \mathrm{m}), 4.62$ $(2 \mathrm{H}, \mathrm{s}), 3.74(3 \mathrm{H}, \mathrm{s}) ;{ }^{13} \mathrm{C} \mathrm{NMR}\left(100 \mathrm{MHz}, \mathrm{CDCl}_{3}\right): \delta 173.8$, $158.2,155.8,144.1,140.4,139.4,136.3,132.8,132.6$,
131.5, 127.8, 127.7, 126.4, 114.0, 113.9, 133.3, 133.2, 64.9, 55.2; HR-MS (SIMS, negative mode): calcd. for $\mathrm{C}_{29} \mathrm{H}_{23} \mathrm{O}_{4}$ $\left[\mathrm{M}-\mathrm{H}^{+}\right](\mathrm{m} / \mathrm{z})$ : 435.1596; found: 435.1604 .

Synthesis of 1: A suspension of compound $5(227 \mathrm{mg}$, $0.52 \mathrm{mmol})$, NHS (60 mg, $0.52 \mathrm{mmol})$ and DCC (113 mg, $0.55 \mathrm{mmol})$ in $\mathrm{CH}_{2} \mathrm{Cl}_{2}(10.0 \mathrm{~mL})$ were stirred for $2 \mathrm{~h}$. After filtration and evaporation under reduced pressure, the yellowish residue was dissolved into acetone $(5.0 \mathrm{~mL})$. Such solution was introduced into an aqueous solution of diphenylalanine 6 (63 mg, $0.52 \mathrm{mmol}$ ) and $\mathrm{NaHCO}_{3}(88 \mathrm{mg}, 1.05$ mmol). The mixture was stirred overnight. After the reaction was complete, $3 \mathrm{~mol} / \mathrm{L} \mathrm{HCl}$ (aq) was added by droplets until $\mathrm{pH}$ reached 3.0. Then, $\mathrm{CH}_{2} \mathrm{Cl}_{2}(20 \mathrm{~mL})$ was added and the organic layer was washed successively with brine and water, and dried over anhydrous $\mathrm{MgSO}_{4}$. After filtration, the solvent was evaporated under reduced pressure. The residue was subjected to column chromatography with $\mathrm{CH}_{2} \mathrm{Cl}_{2} / \mathrm{CH}_{3} \mathrm{OH}(\mathrm{v} / \mathrm{v}, 100 / 1)$ as eluant. Compound 1 was obtained as a yellowish powder $(210 \mathrm{mg})$ in $55 \%$ yield. ${ }^{1} \mathrm{H}$ NMR (400 MHz, $\left.\mathrm{CDCl}_{3}\right): \delta 7.25-7.20(3 \mathrm{H}, \mathrm{m}), 7.18-7.07$ (10H, m), 7.06-6.97 (7H, m), 6.96-6.86 (3H, m), 6.70-6.60 (2H, m), 6.60-6.50 (2H, m), 6.43-6.37 (1H, m), 4.80-4.68 (2H, m), 4.35-4.25 (2H, m), 3.75-3.65 (3H, m), 3.16-3.06 $(2 \mathrm{H}, \mathrm{m}), 3.05-2.96(2 \mathrm{H}, \mathrm{m}) ;{ }^{13} \mathrm{C} \mathrm{NMR}\left(100 \mathrm{MHz}, \mathrm{CDCl}_{3}\right)$ : $\delta 174.0,170.3,168.9,158.2,155.3,132.9,132.6,131.5$, $129.5,129.4,128.9,128.6,127.9,127.8,127.7,127.3$, 126.5, 114.1, 114.0, 113.3, 113.2, 66.9, 55.2, 53.7, 53.4, 37.7, 37.5; HR-MS (SIMS, negative mode): calcd. for $\mathrm{C}_{47} \mathrm{H}_{41} \mathrm{~N}_{2} \mathrm{O}_{6}\left[\mathrm{M}-\mathrm{H}^{+}\right](\mathrm{m} / z)$ : 729.2965; found: 729.2976 .

\section{Results and discussion}

\subsection{Gelation test}

At first the gelation ability of gelator 1 was studied.

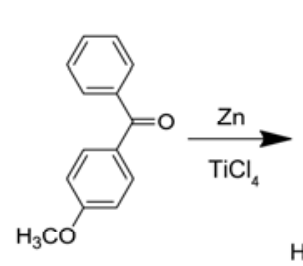

2

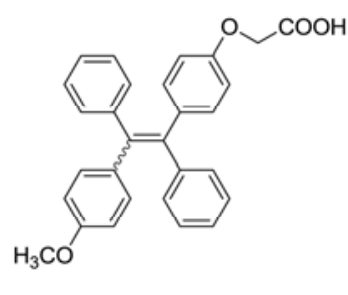

5
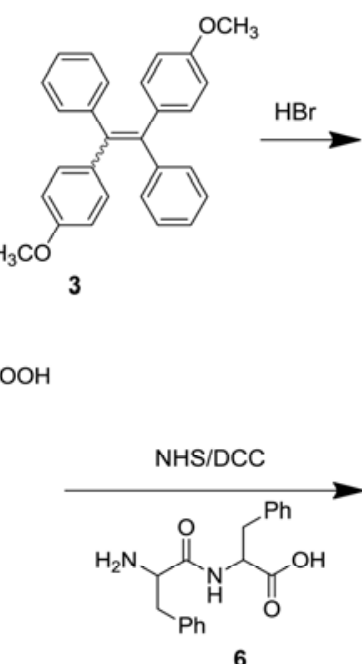

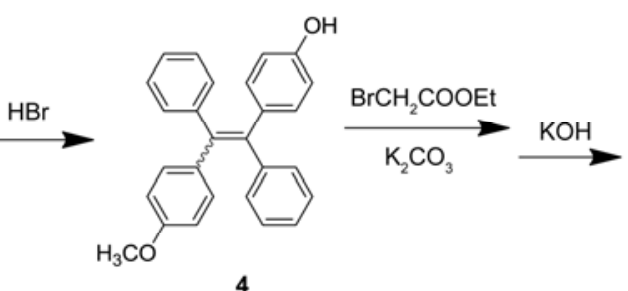

4

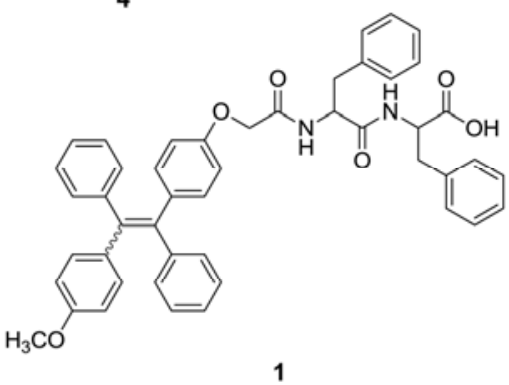

Figure 1 Chemical structure of $\mathbf{1}$ and the synthetic approach. 
Generally, a weighed amount of the gelator and $1.0 \mathrm{~mL}$ of the solvent were placed in a vial, which was sealed and then heated until the gelator was completely dissolved. The solution was allowed to cool down and rest for a while. If the mixture was immobilized when the vial was inverted, then the gel was generated. According to previous reports [14-16], diphenylalanine is a good gelating moiety. However, 1 was hardly soluble in aqueous solution, even after tuning $\mathrm{pH}$ upon addition of $\mathrm{NaOH}(\mathrm{aq})$ or $\mathrm{HCl}(\mathrm{aq})$. Hence the mixture solution of water and organic solvent was used instead. The organic solvents which can be miscible with water, such as $\mathrm{C}_{2} \mathrm{H}_{5} \mathrm{OH}, \mathrm{CH}_{3} \mathrm{OH}, \mathrm{CH}_{3} \mathrm{COCH}_{3}$, THF and $\mathrm{CH}_{3} \mathrm{CN}$, were used for the gelation experiments.

The results of gelation studies are listed in Table 1. Clearly, 1 could gel the first three mixture solvents, namely, $\mathrm{H}_{2} \mathrm{O} / \mathrm{C}_{2} \mathrm{H}_{5} \mathrm{OH}, \mathrm{H}_{2} \mathrm{O} / \mathrm{CH}_{3} \mathrm{OH}$ or $\mathrm{H}_{2} \mathrm{O} / \mathrm{CH}_{3} \mathrm{COCH}_{3}$. With $\mathrm{H}_{2} \mathrm{O}$ $/ \mathrm{C}_{2} \mathrm{H}_{5} \mathrm{OH}(1 / 1, \mathrm{v} / \mathrm{v})$ as an example, to a vial was added a suspension of 1 at the concentration of $6.0 \mathrm{mg} / \mathrm{mL}$; then, 0.5 $\mathrm{mol} / \mathrm{L} \mathrm{NaOH}(\mathrm{aq})$ was added until the mixture turned into a clear homogeneous solution ( $\mathrm{pH} \mathrm{12),} \mathrm{followed} \mathrm{by} \mathrm{the} \mathrm{addi-}$ tion of $1.0 \mathrm{~mol} / \mathrm{L} \mathrm{HCl} \mathrm{(aq)} \mathrm{until} \mathrm{slight} \mathrm{precipitation} \mathrm{ap-}$ peared ( $\mathrm{pH} \mathrm{7.5).} \mathrm{After} \mathrm{that,} \mathrm{the} \mathrm{solution} \mathrm{was} \mathrm{heated} \mathrm{to} \mathrm{a}$ clear solution and rested for about half an hour, a transparent gel was generated. After varying the concentration of $\mathbf{1}$ and $\mathrm{pH}$ of the solution, the critical gelation concentration (CGC) was measured to be $4.0 \mathrm{mg} / \mathrm{mL}$, and critical $\mathrm{pH}$ was 7.5. Figure 2 depicts the photos of the solution and gel of $\mathbf{1}$ under daylight and UV light irradiation, respectively.

\subsection{Characterization of the gel}

After the gel was generated, it was lyophilized to obtain its xerogel as a yellowish fluffy powder. As displayed in Figure 3(a) and (b), the scanning electron microscope (SEM)

Table 1 Gelation studies of gelator $\mathbf{1}$ in different mixture solvents ${ }^{\text {a) }}$

\begin{tabular}{lc}
\hline \multicolumn{1}{c}{ Solvents } & Results \\
\hline $\mathrm{H}_{2} \mathrm{O} / \mathrm{C}_{2} \mathrm{H}_{5} \mathrm{OH}(1 / 1, \mathrm{v} / \mathrm{v})$ & $\mathrm{G}$ \\
$\mathrm{H}_{2} \mathrm{O} / \mathrm{CH}_{3} \mathrm{OH}(1 / 1, \mathrm{v} / \mathrm{v})$ & $\mathrm{G}$ \\
$\mathrm{H}_{2} \mathrm{O} / \mathrm{CH}_{3} \mathrm{COCH}(1 / 1, \mathrm{v} / \mathrm{v})$ & $\mathrm{G}$ \\
$\mathrm{H}_{2} \mathrm{O} / \mathrm{THF}(1 / 1, \mathrm{v} / \mathrm{v})$ & $\mathrm{S}$ \\
$\mathrm{H}_{2} \mathrm{O} / \mathrm{CH}_{3} \mathrm{CN}(1 / 1, \mathrm{v} / \mathrm{v})$ & $\mathrm{S}$ \\
\hline
\end{tabular}

a) G, Gelation; S, Solution.
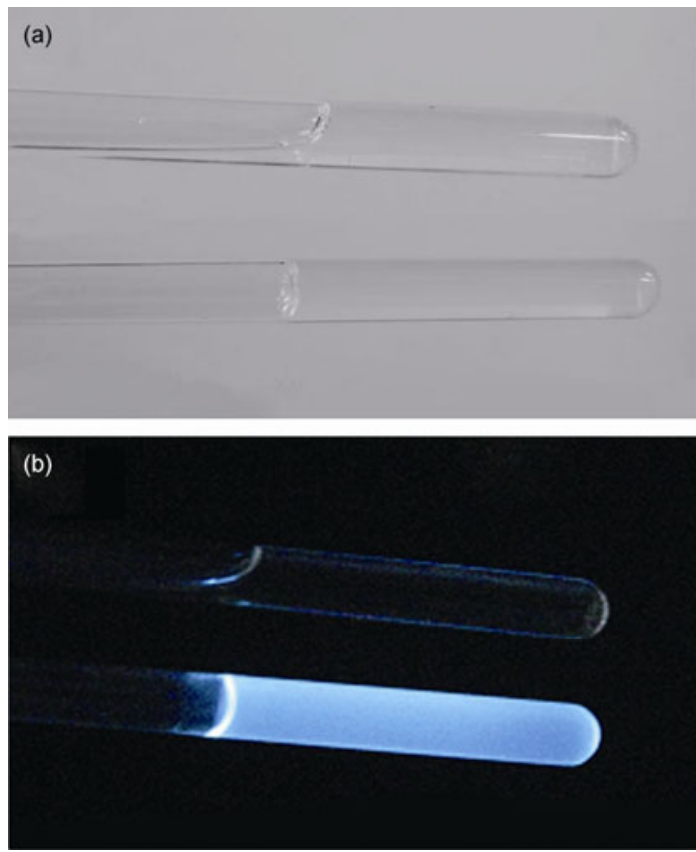

Figure 2 (Color online) (a) Photo of the solution and gel of 1 under daylight. (b) Photo of the solution and gel of 1 under UV light irradiation $\left(\lambda_{\mathrm{ex}}\right.$ $=365 \mathrm{~nm}$ )

micrograph showed that the xerogel was composed of tiny plates with the size of scores of square micrometers, and these tiny plates were entangled into three-dimensional networks. Meanwhile, confocal laser scanning microscope (CLSM) image indicated the xerogel was strongly emissive under UV light irradiation, as shown in Figure 3(c).

The X-ray diffraction (XRD) pattern of the xerogel formed with 1 was examined (Figure 4). A broad diffraction signal was detected with the peak at $1.92^{\circ}$. The corresponding $d$-spacing was $4.61 \mathrm{~nm}$. The molecular length of 1 was $2.36 \mathrm{~nm}$ approximately, hence $d$-spacing may relate to the twofold of molecular length. There were a hydrophobic TPE unit and a hydrophilic diphenylalanine moiety in $\mathbf{1}$. Therefore, the TPE units of neighboring molecules may be aggregated in the interior, for the hydrophobic interactions and $\pi-\pi$ stacking; the diphenylalanine moieties may be assembled in the periphery via the intermolecular hydrogen bonding. In this way, molecules of $\mathbf{1}$ are assembled into interconnected networks leading to gelation as schematically
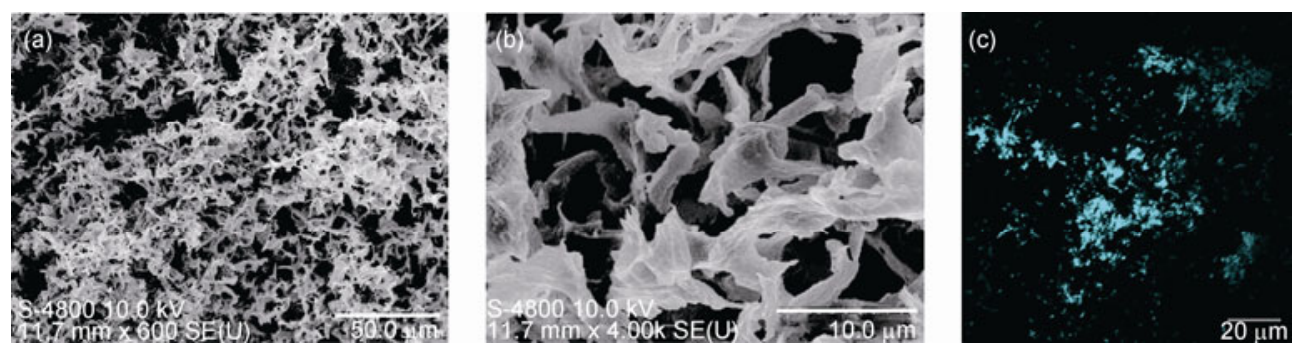

Figure 3 (Color online) (a) SEM image of the xerogel of $\mathbf{1}$; the scale bar is $50 \mu \mathrm{m}$. (b) The magnified image of (a), the scale bar is $10 \mu \mathrm{m}$. (c) CLSM image of the xerogel of $\mathbf{1}\left(\lambda_{\mathrm{ex}}=375 \mathrm{~nm}\right)$; the scale bar is $20 \mu \mathrm{m}$. 


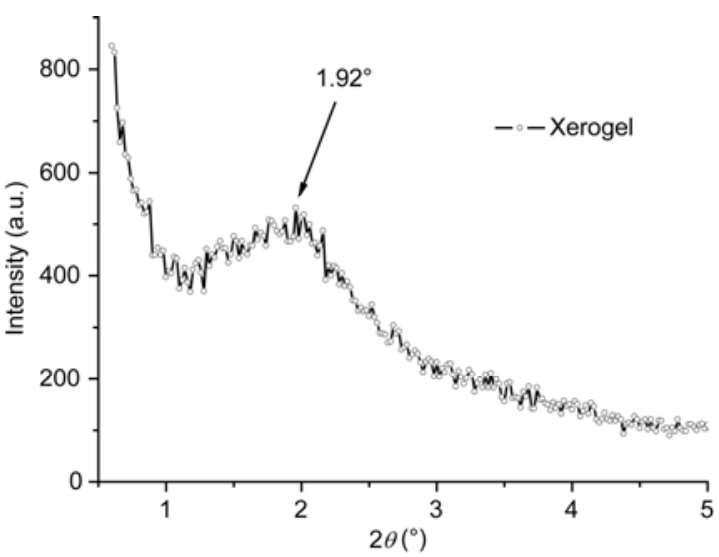

Figure 4 XRD pattern of the xerogel of $\mathbf{1}$.

illustrated in Figure 5.

\subsection{Fluorescence tuning}

We studied the fluorescent properties of $\mathbf{1}$ in the solution and gel states, respectively. As revealed in Figure 2 (b), under UV light irradiation, the solution was almost non-fluorescent, but it emitted bright blue fluorescence after the gel formation. Figure 6 shows the fluorescence spectra of $\mathbf{1}$ in both solution and gel states. Apparently, there was no obvious fluorescence for the solution, while intensive fluorescence emerged upon the gel formation. For instance, the fluorescence intensity at $455 \mathrm{~nm}$ increased by nearly 80 times after gelation. This is in accordance with the CLSM image of xerogel as shown in Figure 3(c). Such fluorescence enhancement should be attributed to the TPE unit in $\mathbf{1}$. It is known that TPE molecules are weakly fluorescent in solutions because of the internal rotations, but they become strongly emissive after aggregation [33-35]. Therefore, the fluorescence enhancement observed for $\mathbf{1}$ after gelation should be ascribed to the intermolecular interactions which lead to gelation and simultaneously restrict the internal rotations within TPE moiety.

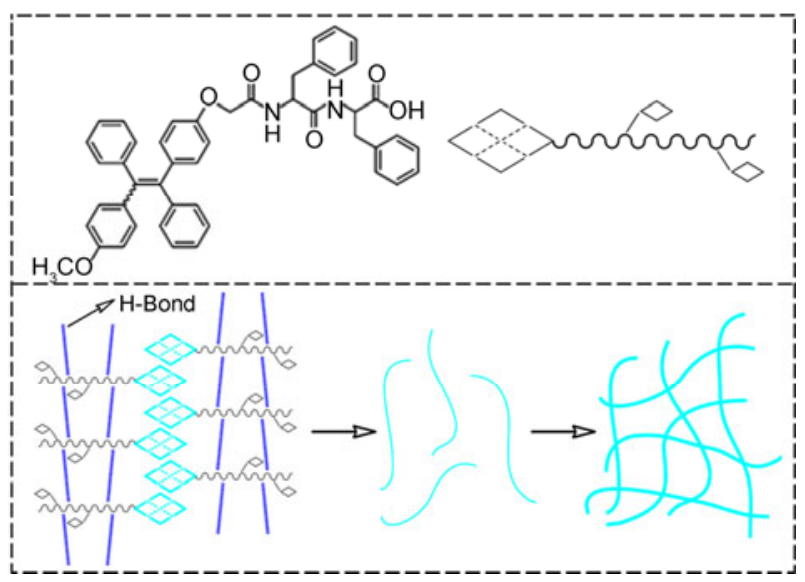

Figure 5 (Color online) The schematic illustration of the gelation with 1.

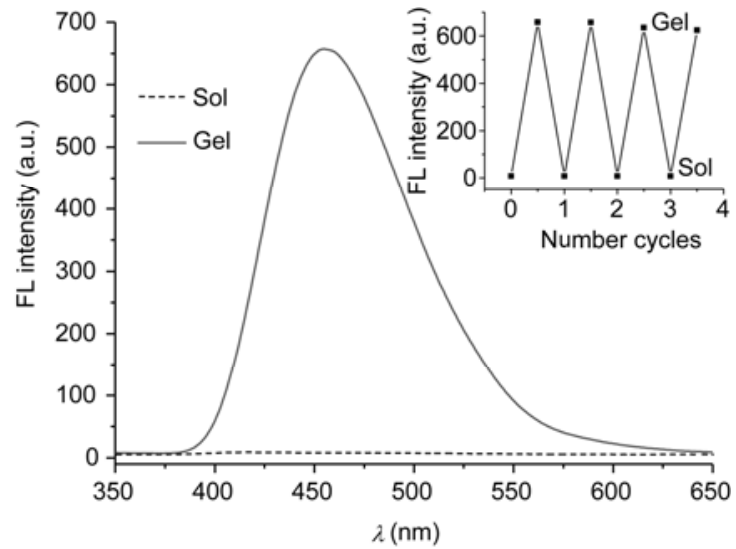

Figure 6 The fluorescence spectra of $\mathbf{1}(6.0 \mathrm{mg} / \mathrm{mL}, \mathrm{pH} 7.5)$ in the solution state and gel state, respectively; inset shows the reversible variation of the emission intensity at $455 \mathrm{~nm}$ upon the sol-gel transition $\left(\lambda_{\mathrm{ex}}=340 \mathrm{~nm}\right)$.

Interestingly, the fluorescence intensity of $\mathbf{1}$ can be reversibly tuned upon the gel-sol transition as depicted in the inset of Figure 6. For instance, the fluorescence intensity of the gel of $1(6.0 \mathrm{mg} / \mathrm{mL})$ from $\mathrm{H}_{2} \mathrm{O} / \mathrm{C}_{2} \mathrm{H}_{5} \mathrm{OH}(1 / 1, \mathrm{v} / \mathrm{v}, \mathrm{pH}$ 7.5) was high; however, after heating the gel was transformed into the solution which was almost non-emissive. Further cooling led to the formation of fluorescent gel again. In this way, the fluorescence of $\mathbf{1}$ can be switched on and off reversibly for several times.

\section{Conclusions}

A new gelator 1 based on TPE and diphenylalanine was synthesized. The gel can be formed with $\mathbf{1}$ in some miscible mixtures of water and organic solvents, such as $\mathrm{H}_{2} \mathrm{O}$ / $\mathrm{C}_{2} \mathrm{H}_{5} \mathrm{OH}(1 / 1, \mathrm{v} / \mathrm{v}, \mathrm{pH} 7.5)$. The solution of 1 was almost non-emissive, but the fluorescence was remarkably enhanced accompanying the gel formation. The gel can be easily and reversibly heated to the solution state, showing good thermal-reversibility. Accordingly, the fluorescence can be tuned "on-off" reversibly upon the gel-sol phase transition.

This work was supported by the National Natural Science Foundation of China (50973120, 21021091), the National Basic Research Program of China (2011CB808401) and Chinese Academy of Sciences.

1 Terech P, Weiss R G. Low molecular mass gelators of organic liquids and the properties of their gels. Chem Rev, 1997, 97: 3133-3160

2 Yang X Y, Zhang G X, Zhang D Q. Stimuli responsive gels based on low molecular weight gelators. J Mater Chem, 2012, 22: 38-50

3 Žinić M, Vögtle F, Fages F. Cholesterol-based gelators. Top Curr Chem, 2005, 256: 39-76

4 Wang C, Chen Q, Sun F, et al. Multistimuli responsive organogels based on a new gelator featuring tetrathiafulvalene and azobenzene groups: Reversible tuning of the gel-sol transition by redox reactions and light irradiation. J Am Chem Soc, 2010, 132: 3092-3096

5 Chen Q, Zhang D Q, Zhang G X, et al. New cholesterol-based gelators with maleimide unit and the relevant michael adducts: 
Chemoresponsive organogels. Langumir, 2009, 25: 11436-11441

6 Fages F, Vögtle F, Žinić M. Systematic design of amide- and urea-type gelators with tailored properties. Top Curr Chem, 2005, 256: 77-131

7 Wang C, Zhang D Q, Zhu D B. A Low-molecular-mass gelator with an electroactive tetrathiafulvalene group: Tuning the gel formation by charge-transfer interaction and oxidation. J Am Chem Soc, 2005, 127: 16372-16373

8 Yang X Y, Zhang G X, Zhang D Q, et al. A new ex-TTF-based organogelator: Formation of organogels and tuning with fullerene. Langmuir, 2010, 26: 11720-11725

9 Wang M, Zhang D Q, Zhang G X, et al. Fluorescence enhancement upon gelation and thermally-driven fluorescence switches based on tetraphenylsilole-based organic gelators. Chem Phys Lett, 2009, 475: 64-67

10 Araki K, Yoshikawa I. Nucleobase-containing gelators. Top Curr Chem, 2005, 256: 133-165

11 Gronwald O, Shinkai S. Sugar-integrated gelators of organic solvents. Chem Eur J, 2001, 7: 4328-4334

12 Jung J H, Shinkai S, Shimizu T. Preparation of mesoscale and macroscale silica nanotubes using a sugar-appended azonaphthol gelator assembly. Nano Lett, 2002, 2: 17-20

13 Kobayashi H, Friggeri A, Koumoto K, et al. Molecular design of "super" hydrogelators: Understanding the gelation process of azobenzene-based sugar derivatives in water. Org Lett, 2002, 4: $1423-1426$

14 Smith A M, Williams R J, Tang C, et al. Fmoc-diphenylalanine self assembles to a hydrogel via a novel architecture based on $\pi-\pi$ interlocked $\beta$-sheets. Adv Mater, 2008, 20: 37-41

15 Li X M, Li J Y, Gao Y, et al. Molecular nanofibers of olsalazine form supramolecular hydrogels for reductive release of an antiinflammatory agent. J Am Chem Soc, 2010, 132: 17707-17709

16 Yang Z M, Liang G L, Xu B. Enzymatic hydrogelation of small molecules. Acc Chem Res, 2008, 41: 315-326

17 Yang Z M, Liang G L, Ma M L, et al. Conjugates of naphthalene and dipeptides produce molecular hydrogelators with high efficiency of hydrogelation and superhelical nanofibers. J Mater Chem, 2007, 17 : $850-854$

18 Gao P, Zhan C L, Liu L Z, et al. Inter- and intra-molecular H-bonds induced different nanostructures from a multi-H-bonding (MHB) amphiphile: Nanofibers and nanodisks. Chem Commun, 2004, 1174-1175

19 Zhan C L, Gao P, Liu M H. Self-assembled helical spherical-nanotubes from an L-glutamic acid based bolaamphiphilic low molecular mass organogelator. Chem Commun, 2005, 462-464

20 Gao P, Zhan C L, Liu M H. Controlled synthesis of double- and multiwall silver nanotubes with template organogel from a bolaamphiphile. Langumir, 2006, 22: 775-779
21 Jayawarna V, Ali M, Jowitt T A, et al. Nanostructured hydrogels for three-dimensional cell culture through self-assembly of fluorenylmethoxycarbonyl-dipeptides. Adv Mater, 2006,18: 611-614

22 Telodano S, Williams R J, Jayawarna V, et al. Enzyme-triggered self-assembly of peptide hydrogels via reversed hydrolysis. J Am Chem Soc, 2006, 128: 1070-1071

23 Ajayaghosh A, George S J. First phenylenevinylene based organogels: Self-assembled nanostructures via cooperative hydrogen bonding and $\pi$-stacking. J Am Chem Soc, 2001, 123: 5148-5149

24 Ajayaghosh A, Varghese R, Praveen V K, et al. Evolution of nano- to microsized spherical assemblies of a short oligo( $p$-phenyleneethnylene) into superstructured organogels. Agew Chem Int Ed, 2006, 45: 3261-3264

25 Babu S S, Praveen V K, Prasanthkumar S, et al. Self-assembly of oligo(para-phenylenevinylene)s through arene-perfluoroarene interactions: $\pi$ gels with longitudinally controlled fiber growth and supramolecular exciplex-mediated enhanced emission. Chem Eur J, 2008, 14: 9577-9584

26 Hirst A R, Smith D K. Dendritic gelators. Top Curr Chem, 2005, 256: 237-273

27 Yang X Y, Zhang G X, Zhang D Q, et al. Self-assembly of a dendron-attached tetrathiafulvalene: Gel formation and modulation in the presence of chloranil and metal ions. Small, 2012, 8: 578-584

28 Chen Q, Feng Y, Zhang D Q, et al. Light-triggered self-assembly of a spiropyran-functionalized dendron into nano-/micrometer-sized particles and photoresponsive organogel with switchable fluorescence. Adv Funct Mater, 2010, 20: 36-42

29 Chen Q, Zhang D Q, Zhang G X, et al. Multicolor tunable emission from organogels containing tetraphenylethene, perylenediimide, and spiropyran derivatives. Adv Funct Mater, 2010, 20: 3244-325

30 Manna S, Saha A, Nandi A K. A two component thermoreversible hydrogel of riboflavin and melamine: Enhancement of photoluminescence in the gel form. Chem Commun, 2006, 4285-4287

31 Saha A, Manna S, Nandi A K. Temperature and $\mathrm{pH}$ sensitive photoluminescence of riboflavin-methyl cellulose hydrogel: Towards AND molecular logic gate behaviour. Soft Matter, 2009, 5: 3992-3996

32 An B K, Lee D S, Lee J S, et al. Strongly fluorescent organogel system comprising fibrillar self-assembly of a trifluoromethyl-based cyanostilbene derivative. J Am Chem Soc, 2004, 126: 10232-10233

33 Hong Y N, Lam J W Y, Tang B Z. Aggregation-induced emission. Chem Soc Rev, 2011, 40: 5361-5388

34 Wang $\mathrm{M}$, Zhang $\mathrm{G}$ X, Zhang D Q, et al. Fluorescent bio/ chemosensors based on silole and tetraphenylethene luminogens with aggregation-induced emission feature. J Mater Chem, 2010, 20: 1858-1867

35 Sun F, Zhang G X, Zhang D Q, et al. Aqueous fluorescence turn-on sensor for $\mathrm{Zn}^{2+}$ with a tetraphenylethylene compound. Org Lett, 2011, 13: $6378-6381$

Open Access This article is distributed under the terms of the Creative Commons Attribution License which permits any use, distribution, and reproduction in any medium, provided the original author(s) and source are credited. 